\title{
云南新平哀牢山秋季夜间网捕鸟类的影响因素
}

\author{
杨 婷 ${ }^{1,2}$, 杨晓君 ${ }^{1,}{ }^{*}$, 王紫江 ${ }^{3}$, 刘 $\frac{\text { 鲁明 }}{1}$, 安庆媛 ${ }^{3}$, 张宏雨 ${ }^{4}$, 李国松 ${ }^{4}$, 施文安 ${ }^{4}$ \\ (1. 中国科学院昆明动物研究所, 云南 昆明 650223；2. 中国科学院研究生院, 北京 100049; \\ 3. 昆明鸟类协会, 云南 昆明 650021；4. 哀牢山国家级自然保护区新平管理局, 云南 新平 653400）
}

\begin{abstract}
摘要: 2007-09-05-2007-11-05 和 2008-09-03-2008-11-07 期间, 在云南省新平县哀牢山金山 Y $口\left(23^{\circ} 57^{\prime} \mathrm{N}\right.$, $101^{\circ} 30^{\prime} \mathrm{E}$ ) 对影响秋季夜间网捕鸟类组成因素进行了调查。主要利用温湿度表和定性观察对各因素进行判断。其 研究结果表明, 地理特点是影响夜间网捕鸟类种类的主要因素; 气象条件是影响夜间网捕鸟类种类和数量的重要 因素。气象条件中的风向、风力、雾以及月相周期对夜间网捕鸟类数量和种类的影响极其显著 $(P<0.01)$ 。风向 的影响比风力大, 其中, 在西南风大雾新月或者在西南风大雾残月期间, 夜间网捕鸟类数量和种类最多; 光也是 夜间网捕鸟类的必要条件。然而, 温湿度对夜间网捕鸟类数量和种类影响不显著。
\end{abstract}

关键词: 哀牢山; 金山Ү口; 夜间网捕鸟类; 气候因素；地理因素

中图分类号: Q958.112; Q958.13; Q959.7 文献标识码: A 文章编号: 0254-5853-(2009)04-0411-07

\section{Influencing Factors of Birds Captured at Night in Ailao Mountain, Xinping County, Yunnan Province}

\author{
YANG Ting ${ }^{1,2}$, YANG Xiao-jun ${ }^{1,}{ }^{*}$, WANG Zi-jiang ${ }^{3}$, LIU Lu-ming ${ }^{1}$, AN Qing-yuan ${ }^{3}$, \\ ZHANG Hong-yu ${ }^{4}$, LI Guo-song ${ }^{4}$, SHI Wen-an ${ }^{4}$ \\ (1. Kunming Institute of Zoology, the Chinese Academy of Sciences, Kunming Yunnan 650223, China; 2. Graduate School of the Chinese \\ Academy of Sciences, Beijing, 100049, China; 3. Kunming Birds Conservation Association, Kunming $\quad 650021$, China; \\ 4. Xinping Bureau of Yunnan Ailao Mountains National Reserves, Xinping $\quad 653400$, China)
}

\begin{abstract}
The influencing factors of birds captured at night were investigated by light trapping at Jinshan Yakou $\left(23^{\circ} 57^{\prime} \mathrm{N}, 101^{\circ} 30^{\prime} \mathrm{E}\right)$ of Ailao Mountain, Xinping County, Yunnan Province from 5th September to 5th November 2007 and from 3rd September to 7th November 2008. The influencing factors were analyzed by using hygrothermograph and qualitative analysis. Geography conditions had a great effect on the bird species captured at night. Weather was also an important factor influencing the number and species of birds captured at night. Statistical analysis showed that wind direction, wind force, fog and lunar phase had a significant effect on the species and number of birds captured at night $(P<0.01)$. However, the effect of wind direction was more obvious than that of wind force. More birds and species were captured during nights with a southwestern wind, fog, crescent moon and old moon. In addition to light is a necessary condition for trapping. But temperature and humidity had no significant effect on the number and species of birds captured at night.
\end{abstract}

Key words: Ailao Mountain; Jinshan yakou; Birds captured at night; Climate factors; Geography factors

鸟类迁徙受到许多因素的制约, 包括其内部的 生理因素和外部环境因素 (如日照长度、温度、降 雨、风等)，其中天气因素作用较强 (Zheng, 1995; Zhang \& Yang, 1997)。气候因素对鸟类飞行的影响 有关研究报道较多。风向、风速都能影响迁徙鸟类
的飞行 (Kenneth, 1973; Peter, 1993; Robert, 1997; Susanne \& Anders, 2000; Felix, 2006; Kasper et al, 2006 )。对夜间迁徙鸟类飞行的影响因素除了风， 还有雾、月相周期等能见度因素 (Alerstam，1976; Peter, 1993)。某地温度也会影响鸟类开始迁徙的 
时间和顺序 (Judy \& Emiel, 2006), 温度的增加会 影响春季迁徙鸟类网捕数量（Peter et al，2005)。

国内有关夜间迁徙鸟类的研究报道较多, 如云 南大理巍山（Chu et al，1998; Yang et al，2004)、 湖南隆回 “打鸟坳” (Tang et al, 2003)、江西遂川 候鸟通道 (Xiao et al, 2005)、广西大苗山 “打鸟坳”

(Jiang et al，2006)、云南南涧风凰山 (Huang et al, 2006）和云南新平哀牢山（Zhang，2009）等。然 而, 这些报道及研究仅用数据或者根据以往经验简 单说明夜间网捕数量与雾、风向和月光有关系。为 了进一步科学地、定量地了解夜间网捕鸟类组成与 环境因素的关系，笔者于 2007 年和 2008 年的 911 月在云南省玉溪市新平县哀牢山金山Y口对影 响夜间网捕迁徙鸟类组成因素进行调查, 并与同属 于云南哀牢山山系的巍山、属于无量山山系的南润 凤凰山的结果进行了比较分析, 现将有关结果报道 如下:

\section{1 研究地点与方法}

\section{1 研究地点}

哀牢山金山Ү口地处哀牢山中段, 位于玉溪市 新平县和普洱市镇源县的交界处, 是哀牢山沿山脊 方向上两个山峰间呈马鞍状的明显下凹处, 因地处 金山而得名。地理坐标为东经 $101^{\circ} 30^{\prime}$, 北纬 $23^{\circ} 57^{\prime}$ 。 海拔在 2180-2360 $\mathrm{m}$ 之间。冬夏季分别受两种不同 的大气候环流影响, 冬季 (11 月到次年 4 月), 受 来自阿拉伯沙漠和印度洋北部大陆上空干暖气候 控制, 空气干暖、降水少、晴天多、日照充足、昼 夜温差大。夏季 (5-10 月) 受印度洋和太平洋暖 湿气流的控制, 空气湿度大、降雨多, 日照较少、 昼夜温差小, 多雾 (Zhang, 2009)。

\section{2 研究方法}

1.2.1 调查方法 野外调查时间为 2007 年 9 月 5 日- 11 月 5 日和 2008 年 9 月 3 日- 11 月 7 日, 共 117 天。每晚 20:00 至次日 06:00, 利用 4 张 ATX (孔 径: $36 \mathrm{~mm}$, 长: $12 \mathrm{~m}$, 高: $2.6 \mathrm{~m}$, 舀数: 5) 专用 捕鸟雾网和 4 台 $300 \mathrm{~W}$ 的白炽灯进行灯光诱捕。调 查期间, 在每个 $120 \mathrm{~min}$ 时刻点利用 WS-1 型毛发 温湿度表记录一次空气中的温湿度。网捕期间, 参 照蒲福风级表 (Beaufort wind force scale) 进行定性 记录风力, 风力等级分为 $1 \sim 2$ 级, $2 \sim 3$ 级, $3 \sim 4$ 级, $4 \sim 5$ 级, 5 6 级, 6 7 级共 6 个等级。在夜 间网捕时间内, 对风向和雾天等气候因素也采用定
性观察, 将雾按能见度小于和大于 $15 \mathrm{~m}$ 分别定为 大雾和非大雾两种类型。将月相周期分为新月（农 历初一至初六)、上弦月（初七至农历十二）、满月 (农历十三至十八)、下弦月（农历十九至二十四） 和残月（农历二十五至三十） 5 类。

1.2.2 数据分析 所有数据均输入计算机中进行 统计分析。将每天夜间记录的 6 个温湿度平均值作 为当日夜间的温湿度, 并把温度划分为 $7 \sim 9^{\circ} \mathrm{C}$ 、 $10 \sim 12^{\circ} \mathrm{C} 、 13 \sim 15^{\circ} \mathrm{C}$ 和 $16 \sim 18^{\circ} \mathrm{C} 4$ 个级别; 湿度 划分为 $80 \% \sim 90 \% 、 91 \% \sim 95 \%$ 和 $96 \% \sim 100 \% 3$ 个 范围。

数据在进行统计分析前, 先对每组数据进行非 参数检验中的单样本 $\mathrm{K}-\mathrm{S}$ 检验, 检验每组数据是否 呈正态分布。如果呈正态分布, 主要用单因素方差 分析 (one-way ANOVA) 和双样本 $T$ 检验 (independent-samples $t$ test); 如果不呈正态分布, 主要采用非参数两个独立样本检验

(two-independent samples test) 中的 Mann-Whitney $U$ 检验和非参数多个独立样本检验 (K-independent samples test）进行分析。所有数据全部在 SPSS 13.0 软件中进行统计分析。

根据非参数 K-S 检验结果, 采用非参数多个独 立样本检验法检验 2007 年和 2008 年 2 年期间温度 和湿度对夜间网捕鸟类种类和数量的影响, 用单因 素方差分析法分析 2007 年和 2008 年温度对鸟类种 类的影响以及 2008 年湿度对岛类种类的影响。应 用非参数两个独立样本检验中的 Mann-Whitney $U$ 检验来检验 2007 年和 2008 年 2 年期间雾和风向对 夜间网捕鸟类种类和数量的影响。单独分析 2007 年和 2008 年时, 用双样本 $T$ 检验 （independent-samples $t$ test）分析 2007 年风向和雾 对夜间网捕鸟类种类的影响, 其余的都是采用非参 数两个独立样本检验中的 Mann-Whitney $U$ 检验。 采用非参数多个独立样本检验法检验风力对夜间 网捕鸟类种类和数量的影响。用非参数多个独立样 本检验法检验 2 年期间月相周期对网捕鸟类数量的 影响以及 2008 年月相周期对网捕鸟类种类和数量 的影响。运用单因素方差分析法分析 2 年期间月相 周期对网捕鸟类种类的影响以及 2007 年月相周期 对网捕鸟类种类和数量的影响。利用偏相关分析 (partial)对风力和风向中一种因素在控制和不控制 的条件下，另外一种因素对夜间鸟类网捕数量的影 响是否一致进行检验。所有数据全部在 SPSS 13.0 
软件中进行统计分析。

\section{2 结 果}

\section{1 气候因素}

2.1.1 温、湿度和雾 非参数多个独立样本检验法 （K-independent samples test）检验表明：2007 和 2008 年两年期间温度对网捕的种类和数量均无显 著影响; 但分别对 2007 和 2008 年进行分析, 2007 和 2008 年不同温度下的网捕数量差异都极显著 $(P<0.01)$ （表 1)。单因素方差分析（one-way ANOVA）分析表明： 2008 年的温度对网捕鸟类种 类变化也有极显著影响 $(P<0.01)$, 而 2007 年温度
对网捕鸟类种类无显著影响（表 1)。

两年期间，湿度为 $80 \%$ 90\%范围时，平均网 捕鸟类 11 种 78 只 $(n=14)$; 湿度为 $91 \% \sim 95 \%$ 范 围时，平均网捕鸟类 7 种 34 只 $(n=28)$; 为 $96 \%$ $100 \%$ 范围时, 平均网捕鸟类 10 种 77 只 $(n=76)$ 。 非参数多个独立样本检验法 (K-independent samples test）检验得出: 无论是两年数据还是分年度, 湿度 对网捕的种类和数量均无显著的影响 $\left(\chi_{2}^{2}=2.528 \sim\right.$ $2.830, P=0.243 \sim 0.283$ )。

Mann-Whitney $U$ 检验表明: 雾对夜间网捕鸟类 数量和种类也都有极显著影响 $(P<0.01)$ (表 2$)$ 。大 雾天气下夜间网捕鸟类数量和种类都显著高于非

表 1 温度对 2007 年和 2008 年哀牢山秋季夜间捕获种类和数量的影响

Tab. 1 The effect of temperature on the number and species of birds captured at night in Ailao Mountain in autumn from 2007 to 2008

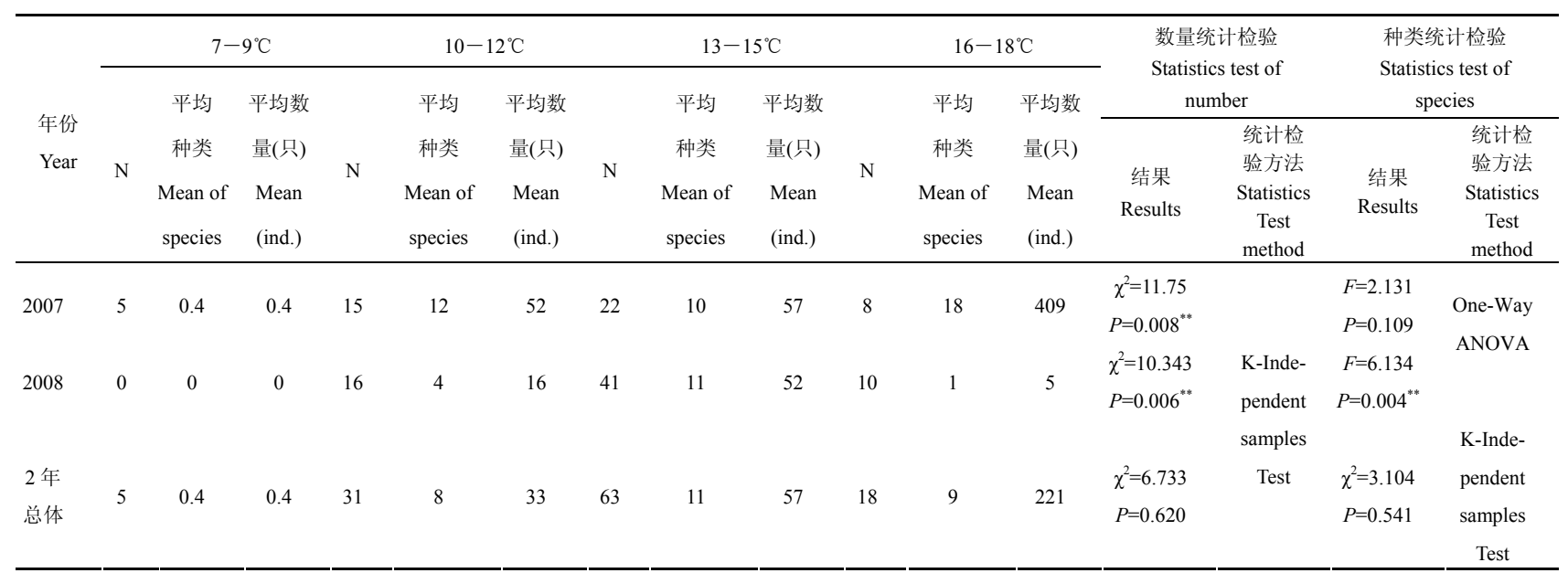

**表示 $P<0.01, n=$ 样本量。

** indicates $P<0.01, n=$ Sample size.

表 2 雾对 2007 年和 2008 年哀牢山秋季夜间捕获种类和数量的影响

Tab. 2 Effect of fog on the number and species of birds captured at night in Ailao Mountain in autumn from 2007 to 2008

\begin{tabular}{|c|c|c|c|c|c|c|c|c|c|c|}
\hline \multirow[b]{3}{*}{$\begin{array}{l}\text { 年份 } \\
\text { Year }\end{array}$} & \multicolumn{4}{|c|}{ 大雾 Fog } & \multicolumn{2}{|c|}{ 非大雾 Mist } & \multirow{2}{*}{\multicolumn{2}{|c|}{$\begin{array}{c}\text { 数量统计检验 } \\
\text { Statistics test of number }\end{array}$}} & \multirow{2}{*}{\multicolumn{2}{|c|}{$\begin{array}{c}\text { 种类统计检验 } \\
\text { Statistics test of species }\end{array}$}} \\
\hline & & 平均数 & & & 平均数 & & & & & \\
\hline & $n$ & $\begin{array}{l}\text { 量(只) } \\
\text { Mean } \\
\text { (ind.) } \\
\end{array}$ & $\begin{array}{l}\text { 平均种类 } \\
\text { Mean of } \\
\text { Species }\end{array}$ & $n$ & $\begin{array}{l}\text { 量(只) } \\
\text { Mean } \\
\text { (ind.) } \\
\end{array}$ & $\begin{array}{l}\text { 平均种类 } \\
\text { Mean of } \\
\text { Species }\end{array}$ & 结果 Results & $\begin{array}{c}\text { 统计检 } \\
\text { 验方法 } \\
\text { Statistics test } \\
\text { method } \\
\end{array}$ & 结果 Results & $\begin{array}{c}\text { 统计检 } \\
\text { 验方法 } \\
\text { Statistics test } \\
\text { method }\end{array}$ \\
\hline 2007 年 & 23 & 267 & 18 & 27 & 15 & 5 & $\begin{array}{l}U=106.500 \\
P=0.000^{* * *}\end{array}$ & & $\begin{array}{l}t=3.842 \\
P=0.001^{* * *}\end{array}$ & $\begin{array}{l}\text { Independent- } \\
\text { Samples } T \\
\text { Test }\end{array}$ \\
\hline 2008 年 & 21 & 88 & 16 & 46 & 12 & 5 & $\begin{array}{l}U=155.500 \\
P=0.000^{* * *}\end{array}$ & $\begin{array}{c}\text { Mann-Whitney } \\
U \text {-test }\end{array}$ & $\begin{array}{l}U=147.500 \\
P=0.000^{* * *}\end{array}$ & $\begin{array}{l}\text { Mann- } \\
\text { Whitney }\end{array}$ \\
\hline $\begin{array}{l}\text { 总计 } \\
\text { Total }\end{array}$ & 44 & 161 & 17 & 73 & 7 & 5 & $\begin{array}{l}U=450.000 \\
P=0.000^{* * *}\end{array}$ & & $\begin{array}{l}U=513.000 \\
P=0.000^{* *}\end{array}$ & $U$-test \\
\hline
\end{tabular}

***表示 $P<0.001, n=$ 样本量。

*** indicates $P<0.001, n=$ Sample size. 
大雾天气 (表 2)。

2.1.2 风向及风力 2007 和 2008 年两年间, 西南 风时, 平均每天夜间捕获鸟类 14 种 107 只 $(n=44)$, 而风向为东北风时, 平均每天夜间捕获鸟类 2 种 5 只 $(n=46)$ 。Mann-Whitney $U$ 检验表明: 两年期间 风向对夜间网捕鸟类数量和种类的影响极其显著 $(P<0.01)$ (表 3 )。非参数多个独立样本检验 （K-independent samples test）表明：风力对夜间网 捕鸟类数量和种类具有极显著的影响 $\left(\chi^{2} 5=17.994 \sim 18.187, P=0.003\right)$; 进一步分析显示, 2007 年风力大小对夜间网捕鸟类种类和数量影响 极其显著（ $\chi^{2} 5=16.087 \sim 16.416, P=0.006 \sim 0.007$ ), 而 2008 年各风力等级下的网捕鸟类种类和数量无 显著差异 $\left(\chi^{2} 5=7.453 \sim 7.546, P=0.183 \sim 0.189\right)$ 。 当风力达到 4 级以上时, 网捕鸟类种类和数量为 0 (图 1)。

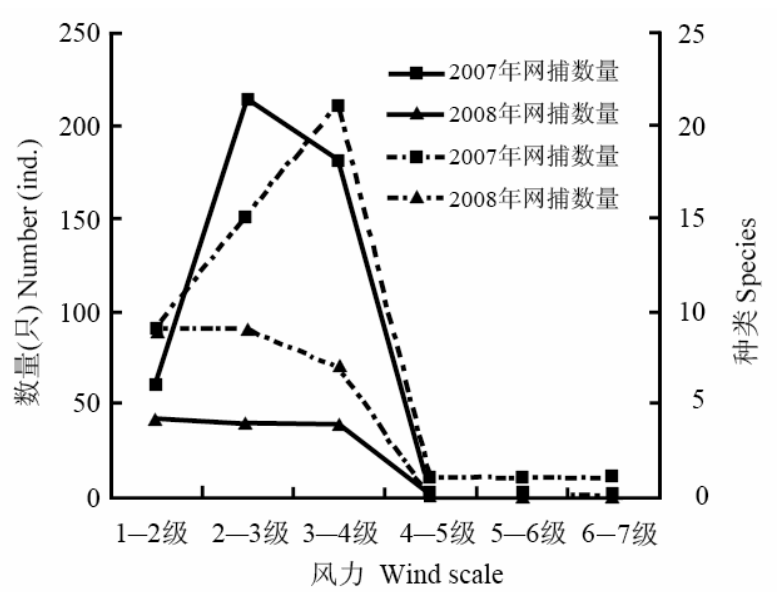

图 1 风力对 2007 年和 2008 年哀牢山秋季夜间捕获 鸟类数量及其种类的影响

Fig. 1 The effect of wind scale on the number and species of birds captured with at night in Ailao Mountain in autumn from 2007 to 2008

表 3 风向对 2007 年和 2008 年哀牢山秋季夜间网捕鸟类种类和数量的影响

Tab. 3 The effect of wind direction on the number and species of birds captured at night in Ailao Mountain in autumn from 2007 to 2008

\begin{tabular}{|c|c|c|c|c|c|c|c|c|c|c|}
\hline \multirow[b]{3}{*}{$\begin{array}{l}\text { 年份 } \\
\text { Year }\end{array}$} & \multicolumn{3}{|c|}{ 西南风 Southwest wind } & \multicolumn{3}{|c|}{ 东北风 Northeast wind } & \multirow{2}{*}{\multicolumn{2}{|c|}{$\begin{array}{c}\text { 数量统计检验 } \\
\text { Statistics test of number }\end{array}$}} & \multirow{2}{*}{\multicolumn{2}{|c|}{$\begin{array}{c}\text { 种类统计检验 } \\
\text { Statistics test of species }\end{array}$}} \\
\hline & & 平均数 & 平均 & & 平均数 & 平均 & & & & \\
\hline & $n$ & $\begin{array}{l}\text { 量(只) } \\
\text { Mean } \\
\text { (ind.) }\end{array}$ & $\begin{array}{c}\text { 种类 } \\
\text { Mean } \\
\text { Species }\end{array}$ & $n$ & $\begin{array}{l}\text { 量(只) } \\
\text { Mean } \\
\text { (ind.) }\end{array}$ & $\begin{array}{c}\text { 种类 } \\
\text { Mean } \\
\text { Species }\end{array}$ & 结果 Results & $\begin{array}{c}\text { 统计检 } \\
\text { 验方法 } \\
\text { Statistics test } \\
\text { method }\end{array}$ & 结果 Results & $\begin{array}{c}\text { 统计检 } \\
\text { 验方法 } \\
\text { Statistics test } \\
\text { method }\end{array}$ \\
\hline 2007 年 & 26 & 210 & 19 & 24 & 3 & 2 & $\begin{aligned} U & =52.000 \\
P & =0.000^{* * *}\end{aligned}$ & Mann- & $\begin{array}{c}t=6.010 \\
P=0.000^{* * *}\end{array}$ & $\begin{array}{l}\text { Independent- } \\
\text { Samples } T \\
\text { Test }\end{array}$ \\
\hline 2008 年 & 45 & 49 & 11 & 22 & 7 & 2 & $\begin{array}{l}U=225.000 \\
P=0.000^{* * *}\end{array}$ & $\begin{array}{c}\text { Whitney } \\
U \text {-test }\end{array}$ & $\begin{array}{l}U=208 . .500 \\
P=0.000^{* * *}\end{array}$ & Mann- \\
\hline $\begin{array}{l}\text { 总计 } \\
\text { Total }\end{array}$ & 71 & 107 & 14 & 46 & 5 & 2 & $\begin{array}{l}U=654.000 \\
P=0.000^{* * *}\end{array}$ & & $\begin{array}{l}U=597.000 \\
P=0.000^{* * *}\end{array}$ & $U$-test \\
\hline
\end{tabular}

\section{2 月 相}

2007 年和 2008 年不同月相下的夜间平均网捕 鸟类种类和数量变化不一致, 2007 年新月和残月期 间平均网捕鸟类数量较其它时期多; 2008 年新月和 上弦月期间网捕鸟类平均数量较其它时期多（表 4 )。经非参数多个独立样本检验 (K-Independent samples Test）表明：2 年期间不同月相周期的夜间 网捕鸟类数量组成及 2008 年不同月相周期数量组 成具有显著差 $(0.01<P<0.05) ， 2008$ 年种类组成差 异不显著 $\left(\chi^{2} 4=9.053, P>0.05\right)$ 。单因素方差分析 (one-Way ANOVA)分析表明: 2 年期间不同月相周 期的夜间网捕鸟类种类及 2007 年不同月相周期下
的鸟类种类和数量组成无显著差异（ $P>0.05 ）($ 表 4)。

\section{3 讨 论}

\section{1 地形因素的影响}

哀牢山金山Y口有大量的候鸟在夜间被捕获， 首先与其地理位置和地形地貌有重要关系：第一, 云南位于候鸟东亚一澳大利西亚迁徙通道上, 同时 也位于中亚一印度迁徙通道的边缘（Zhao，2006), 有很多的候鸟通过云南南北迁徙。大部分中小型候 鸟在云南至少有 2 条迁徙路线，即东线和西线，东 线是由四川盆地沿乌蒙山的西侧, 金沙江河谷向南 
表 4 月相对 2007 年和 2008 年秋季哀牢山秋季夜间捕获鸟类平均数量和种类的影响

Tab. 4 The effect of lunar phase on the number and species of birds captured at night in Ailao Mountain in autumn from 2007 to 2008

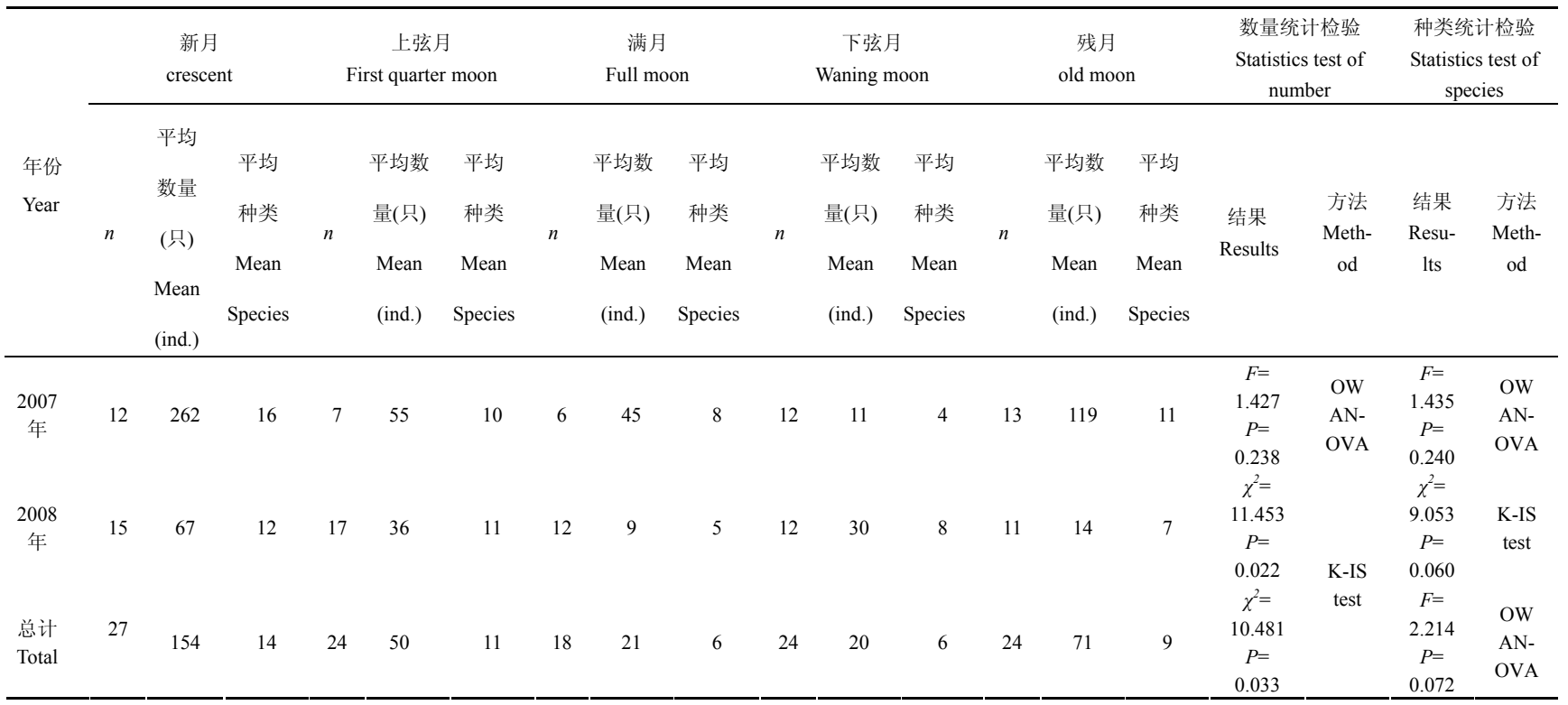

OW ANOVA: One way ANOVA; K-IS test: K-independent samples test.

迁徙, 西线从青藏高原沿云岭余脉一罗坪山、点苍 山和哀牢山的东坡向南迁徙（Wu \& Li，1999），而 此 “打雀山” 的夜间迁徙鸟类可能属于第二条路线。 第二, 哀牢山呈西北一东南走向, 哀牢山与红河河 谷相对海拔高差均在 1000 米以上, 它高大的山体 成为由北往南迁的候鸟迁徙的天然屏障。第三, 哀 牢山金山Ү口是哀牢山沿山脊方向上两个山峰间 呈马鞍状的明显下凹处, 为了减少能量的消耗, 候 鸟在翻越哀牢山时会选择从下凹处飞过。这与 “打 鸟坳” 的形成是鸟类在迁徙过程由宽面迁徙向狭面 迁徙而形成的特殊自然现象一致 (Jiang et al, 2006), 也与云南巍山 (Yang et al, 2004)、云南南 涧凤凰山（Huang et al，2006）、广西大苗山（Jiang et al，2006）、湖南隆回打鸟坳（Tang et al，2003）、 江西遂川候鸟通道 (Xiao et al, 2005) 等地的地形 特征相似。虽然每个 “打雀山” 形成的地理条件比 较相似, 但是哀牢山金山Ү口与其它 “打雀山” 捕 获的鸟类种类和数量有一定的差异 ( $\mathrm{Chu}$ et al, 1998; Tang et al, 2003; Yang et al, 2004; Xiao et al, 2005; Huang et al, 2006; Jiang et al, 2006)。这种 差异很可能是因为不同种类的候鸟迁徙路线不同, 或者是迁徙时间不同而造成的。

\section{2 气候因素及月相的影响}

哀牢山金山Y口是沿东北一西南的一个下凹
处, 所以在此地存在两种风向即东北风和西南风。 从傍晚的观察看到夜间迁徙鸟是沿着Y口由东北 方向西南方向飞行，故西南风就成为阻碍秋季夜间 迁徙鸟类飞行的因素, 网捕调查结果与白天的观察 结果一致, 所以西南风就成为夜间捕获更多鸟类的 一个必要条件。这调查结果与迁徙鸟类都倾向于在 顺风时飞行 (Alerstam, 1976; Susanne \& Anders, 2000; Kenneth, 2008）一致。

对鸟类在不同风力捕获情况的分析表明, 在 2-4 级风的情况下, 鸟类的捕获较多, 而风力达到 4 级以上, 就没有任何鸟类被捕获，进一步分析表明 2007 年风力为 $2-3$ 级时平均网捕鸟类数量最多, 当风力达到 3 级以上, 夜间平均网捕鸟类数量随着 风力增加而减少。2008 年风力是到达 4 级以上夜间 平均网捕鸟类数量随着风力增加而减少, 2 年的结 果都说明这些夜间网捕鸟类对风力大小具有一定 的承受范围, 而且不同鸟类对不同的风力承受范围 不一致。但风力在一定范围内对这些鸟类影响较 小, 而当风大于 4 级时, 鸟类则很少活动, 这与 Huang (2004) 鸟类在风速达到 $4.5 \mathrm{~m} / \mathrm{s}$ (风力 3 级) 就停止飞行的结果相似。

由于风力和风向对夜间网捕鸟类数量均有影 响, 因此, 利用偏相关分析(partial)对风力和风向中 一种因素在控制和不控制的条件下, 另外一种因素 
对夜间鸟类网捕数量的影响是否一致进行检验。统 计结果表明, 在扣除风力影响情况下, 风向和夜间 网捕鸟类数量相关性极其显著 $(r=-0.265, P=0.004$; $n=117$ ); 在扣除风向影响情况下, 风力和夜间网捕 鸟类数量相关性不显著 $(r=-0.039, P=0.674$, $n=117$ )。可得出结论, 风向对夜间网捕鸟类数量的 影响大于风力对夜间网捕数量的影响。

此次分析结果表明, 在大雾和新月能见度较低 的天气情况下, 夜间网捕鸟类数量最多, 主要是通 过影响夜间飞行鸟类的视觉判断, 从而不会飞行或 者降低飞行高度。这与在高能见度时夜间迁徙鸟类 迁离的比例明显高于低能见度的研究结果一致

(Alerstam, 1976; Peter et al, 1993)。这与国内各 “打雀山” 调查结果也一致 (Chu et al, 1998; Tang et al, 2003; Xiao et al, 2005; Huang et al, 2006; Jiang et al, 2006)。

观察中发现温度虽然对夜间网捕数量也有影 响, 但在不同的年份, 其影响不同, 因此温度可能 不是影响网捕数量的主要因素。

以上分析表明, 夜间网捕鸟类数量和种类受风 向、风力、雾和月相周期的影响。这与云南、广西、 湖南各 “打雀山” 的观察结果相似。风、雾和无月 的天气是 “打雀山” 鸟类汇聚的一个主要原因 (Wei et al, 1983; Chu et al, 1998; Tang et al, 2003; Huang et al, 2006; Jiang et al, 2006; Wang \& Zhao, 2009)。 风力较小的西南风、大雾和无月的天气成为阻碍金 山Y口秋季迁徙鸟类飞行的因素。这说明陆地夜间 迁徙鸟到达和离开都受到天气和月相周期的影响

(Peter et al, 1993; Susanne \& Anders, 2000; Kasper et al, 2006; Kenneth, 2008)。

\section{3 人为影响与鸟类保护}

“打雀山” 或 “打鸟坳” 等夜间捕鸟地点的形 成除上述的地理、气候、月相等自然因素的影响外, 与人类的活动也有重要的关系, 这些地点都是人类 用火光或灯光对鸟类进行诱捕, 光成为影响夜间鸟 类被捕获的前提条件和必备条件。分析这种影响的 原因有两点: 第一, 夜间捕获的这些鸟类可能具有 趋光性, 这结果与广西大苗山打鸟坳鸟类趋光性调 查 (Jiang et al, 2006) 和云南南涧风凰山调查 (Han et al，2007）一致; 第二，能见度低的天气条件， 将影响夜间迁徙鸟类的视觉判断, 从而飞行高度降 低, 但如果发现有光线较好的地方, 自然会朝有光 线的地方飞去，这与夜间迁徙鸟类对光有特殊的敏 感性相似（Wei et al，1983）。由于人为光照对夜间 迁徙鸟类有较大的影响, 在候鸟迁徙路线中相对狭 窄的Y口等处的居民建筑、防火瞭望塔和公路上的 汽车灯光都会对夜间鸟类迁徙造成很大的影响, 如 金山Y口就是由于修建公路而发现的一个候鸟迁 徙的重要通道, 而由于人为光照对鸟类迁徙产生的 不利影响, 因此, 在鸟类的重要迁徙通道附近进行 与此相关的工程建设时需要充分考虑候鸟迁徙的 因素, 避免对候岛的迁徙产生影响。

以上分析结果表明, 影响夜间网捕鸟类种类和 数量的因素不是单一的一种, 而是受到风向、风力、 雾及月相等多种因素的共同影响, 同时也说明云南 鸟类迁徙通道的形成, 与云南的特殊地理位置、地 形地貌特征以及当地的气候条件等因素的综合影 响密切相关, 是当地地理环境、气候条件、鸟类自 身的特点等综合作用的结果。夜间网捕目的是环 志, 环志最终目的是调查当地夜间迁徙鸟类种类和 数量。那么有效地捕获更多的岛类种类和数量, 有 效工作日期应该设在秋季每月新月、上弦月、下弦 月和残月期间，而在满月期间，也就是农历十三到 农历十八期间, 停止监测。当天气条件满足西南风、 大雾, 而且风力在 4 级以下时进行检测; 满足东北 风, 无雾和风力达到 4 级以上的天气, 停止监测。 另外, 从保护的角度而言, 应该重点加大缺少月光、 有雾、逆风等适于捕岛天气的保护巡查力度, 并加 强对当地村民的保护鸟类意识的教育, 严格杜绝人 为用灯光或火光捕杀鸟类。

致谢: 此次野外工作得到了云南省哀牢山自然 保护区新平管理局的杨显明、杨宏、鲁发旺、李勇、 王家和、白绍斌、罗田发等同志无私的帮助, 在此 致以诚挚的谢意! 感谢鸟类组师兄吴飞对野外工作 的帮助, 感谢师兄伍和启、刘强、孔德军、王凯在 数据处理和论文修改方面给予的建议。

\section{参考文献:}

Alerstam T. 1976. Nocturnal migration of thrushes (Turdus spp.) in southern Sweden [J]. Oikos, 27: 457-475. 
Sin, 34(3): 66-73. [楚国忠, 王紫江, 尾崎清明, 张 旭, 钱法文. 1998. 云南隆庆关秋季鸟类环志研究. 林业科学, 34(3): 66-73.]

Felix Liechti. 2006. Birds: blowin' by the wind [J]? J Ornithol, 147: 202-211.

Han LX, Huang SL, Yuan YC, Qiu YL. 2007. Fall migration dynamics of birds on Fenghuang Mountains, Yunnan Province, China [J]. Zool Res, 28(1): 35-40. [韩联宪, 黄石林, 袁玉川, 邱云龙. 2007. 云南南涧风 凰山秋季迁移鸟迁移时序与数量变化. 动物学研究, 28 (1): 35-40.]

Huang SL, Hang LX, Gao SZ, Luo ZY. 2006. Analysis of migratory diversity of fall night in Fenghuang Mountains Nanjian County, Yunnan Province [J]. Zool Res, 27(2): 163-168. [黄石林, 韩联宪, 高 素珍, 罗增阳. 2006. 云南南润风凰山秋季夜间迁移鸟类多样性分 析. 动物学研究, 27(2): 163-168.]

Jiang AW, Zhou F, Wei ZH, Lu Z. 2006. A survey of photo tactic birds in "Daniaoao" of Damiao Mountains, Guangxi [J]. Chn J Zool, 41(6): 129-133. [蒋爱伍, 周 放, 韦振海, 陆 舟. 2006. 广西大苗山 “打 鸟坳” 趋光性鸟类调查. 动物学杂志, 41(6): 129-133.]

Judy SB, Emiel VL. 2006. Is there a connection between weather at departure sites, onset of migration and timing of soaring-bird autumn migration in Israel [J]? Global Ecol Biogeogr, 15: 514-552.

Kasper T, Thomas A, Mikael H, Nils K. 2006. Traveling or stopping of migrating birds in relation to wind: an illustration for the osprey [J]. Behav Ecol, 17(3): 497-502.

Kenneth PA. 2008. The role of weather variables and flight direction in determining the magnitude of nocturnal bird migration [J]. Ecology, 54(4): 1031-1041.

Peter P, Nadav N, Henderson RP, Davia FD. 1993. The effects of weather and lunar cycle on nocturnal migration of landbirds at southeast farallon island, California [J]. Condor, 95: 343-361.

Peter PM, Charles MF, Robert SM, Frank RM. 2005. The influence of climate on the timing and rate of spring bird migration [J]. Oecologia, 142: 307-315.

Robert WB, Tony DW, Nils W, Mary AB. 1997. Wind assistance: a requirement for migration of shorebirds [J]? Auk, 114(3): 456-466.
Susanne ?, Anders H. 2000. Wind selectivity of migratory flight departures in birds [J]. Behav Ecol Sociobiol, 47: 140-144.

Tang W, Deng XJ, Wang B. 2003. Research on migratory birds via Daniaoao of Longhui County in Hunan [J]. J Hunan Polytechn Environ Biol, 9(2): 29-33. 汤 伟, 邓学建, 王 斌. 2003. 湖南隆回打鸟㘬 迁徙鸟类资源的调查研究. 湖南环境生物职业技术学院学报, 9(2): 29-33.]

Wei TH, Liu GZ, Shi WY, Ma SL. 1983. The primary study of bird-migration on Ailao Mountains [M].// Laboratory of Ecology Kunming Branch, Academia Sinica. Research of Forest Ecosystem on Ailao Mountains, Yunnan [. Kinming: Yunnan science and technology press, 297-313.[魏天吴, 刘光佐, 石文英, 马世来. 1983. 哀牢山岛 类迁徙的初步研究. [M] // 中国科学院昆明分院生态研究室. 云南 哀牢山森林生态系统研究. 昆明: 云南科技出版社, 297-313.]

Wu JL, Li ZQ. 1999. Survey on localities of bird capturing in Yunnan [J]. $J$ Yunnan Univ, 21(2): 106-108. [吴京亮, 李宗强. 1999. 云南“打雀点” 的调查研究, 云南大学学报, 21(2): 106-108.]

Xiao FZ, Li MJ, Jiang Y. 2005. The study of migratory birds passage in Suichuan [J]. Jiangxi For Sci Technol, 3: 8-10. [肖放珍, 李茂军, 蒋 勇. 2005. 遂川候鸟通道研究. 江西林业科技, 3: 8-10.]

Yang Y, Wang ZJ, Zhao ZJ, Ma SL. 2004. Research on bird ringing in Niaodaoxiongguan, Weishan County, Yunnan in 2003[J]. Sichuan $J$ Zool, 23(2): 120-122. [杨 荣, 王紫江, 赵正军, 马赛龙. 2004. 云南 巍山鸟道雄关 2003 年度鸟类环志研究简报. 四川动物, $23(2)$ : 120-122.]

Zhang FY, Yang RL. 1997. Bird Migration Research of China [M]. Beijing: China Forestry Publishing House. [张孚允，杨若莉. 1997. 中国鸟类 迁移研究. 北京: 中国林业出版社.]

Zhao XM. 2006. Bird Migration and Bird Flu in the Mainland of China [M]. Beijing: China Forestry Publishing House. [赵学敏. 2006. 中国大陆 野生鸟类迁徙动态与命流感. 北京: 中国林业出版社.]

Zheng GM. 1995. Ornithology [M]. Beijing: Beijing Normal University Press. [郑光美. 1995. 鸟类学. 北京: 北京师范大学出版社.] 